\title{
Male participation in antenatal care and its influence on their pregnant partners' reproductive health care utilization: insight from the 2015 Afghanistan Demographic and Health Survey
}

\author{
Sharifullah Alemi, Keiko Nakamura*(D), Mosiur Rahman and Kaoruko Seino \\ Department of Global Health Entrepreneurship, Division of Public Health, Graduate School of Tokyo Medical and Dental \\ University, Tokyo, Japan \\ ${ }^{\star}$ Corresponding author. Email: nakamura.ith@tmd.ac.jp
}

(Received 04 September 2019; revised 08 April 2020; accepted 09 April 2020; first published online 15 June 2020)

\begin{abstract}
Afghanistan has made remarkable progress in reducing maternal mortality over the past few decades, and male participation in their pregnant partner's reproductive health care is crucial for further improvement. This study aimed to examine whether male attendance at antenatal care (ANC) with their pregnant partners might be beneficially associated with the degree of utilization of reproductive health care by the pregnant partners. Data for 2660 couples (women aged 16-49 years) were taken from the 2015 Afghanistan Demographic and Health Survey (AfDHS). Bivariate and multivariate logistic regression models were employed to explore the association between male attendance at ANC with their pregnant partners and reproductive health care utilization outcomes, including adequate utilization (four or more visits) of ANC services, ANC visits during the first trimester (up to 12 weeks) of pregnancy, rate of blood and urine testing during pregnancy, rate of institutional delivery and utilization of postnatal check-up services. The results indicated that the rate of male attendance at ANC with their pregnant partners was $69.4 \%$. After controlling for covariates, pregnant partners who were accompanied to ANC by their male partners were more likely to adequately utilize ANC services (AOR=1.42; 95\% CI: 1.18-1.71), commence ANC visits even during the first trimester ( $\mathrm{AOR}=1.21 ; 95 \% \mathrm{CI}: 1.03-1.42$ ), give birth at a health facility $(\mathrm{AOR}=1.23$; $95 \% \mathrm{CI}: 1.03-1.47)$ and present themselves for postnatal check-ups (AOR=1.24; $95 \% \mathrm{CI}$ : 1.04-1.47) than those who were not accompanied by them. The study demonstrated that participation of male partners in ANC was positively associated with their pregnant partners' utilization of reproductive health care services in Afghanistan. The findings suggest that, to improve maternal and child health outcomes in the country, it would be worthwhile implementing interventions to encourage male partners to become more engaged in the ANC of their pregnant partners.
\end{abstract}

Keywords: Male involvement; Maternal autonomy; Reproductive health

\section{Introduction}

Globally, reduction of maternal mortality is recognized as a critical public health priority (Say et al., 2014). In 2015, the World Health Organization (WHO) estimated that about 830 women die each day from pregnancy- and childbirth-related complications around the world, and that 99\% of these maternal deaths occur in developing countries (Alkema et al., 2016). Despite

( The Author(s), 2020. Published by Cambridge University Press on behalf of Journal of Biosocial Science. This is an Open Access article, distributed under the terms of the Creative Commons Attribution-NonCommercial-NoDerivatives licence (http://creativecommons.org/ licenses/by-nc-nd/4.0/), which permits non-commercial re-use, distribution, and reproduction in any medium, provided the original work is unaltered and is properly cited. The written permission of Cambridge University Press must be obtained for commercial re-use or in order to create a derivative work. 
encouraging strides against maternal mortality, Afghanistan still bears a high burden of maternal mortality, estimated at 1291 per 100,000 live births (CSO et al., 2016). Given this statistic, there is a growing need to promote interventions to reverse the current trend of maternal deaths. One such intervention is encouraging active male involvement in their pregnant partners' utilization of reproductive health care services, which is critical, owing to the well-known positive effects of women's health-seeking behaviours on maternal and neonatal health outcomes.

According to a joint report by UNICEF and WHO in 2015, the median coverage rate of at least four ANC visits during a previous pregnancy was 55\%, with the lowest baseline coverage being in Afghanistan, at only 15\% (Requejo et al., 2015). Other key reproductive health care utilization variables were also reported to be low in the country; only $30 \%$ of women received ANC during the first trimester of pregnancy, and only $40 \%$ and $30 \%$ of pregnant women received urine and blood testing during pregnancy, respectively. Furthermore, only $48 \%$ of women delivered at a health facility and $40 \%$ attended a postnatal check-up within the first 2 days after delivery. Antenatal care visits serve as an ideal entry point for reducing preventable maternal and neonatal morbidity and mortality, where pregnant women and families receive essential consultations and services for safe pregnancy and delivery. Male attendance at ANC with their pregnant partners could improve their access to, and knowledge of, maternal and neonatal health issues, which are conducive to favourable reproductive health outcomes (Yargawa \& Leonardi-Bee, 2015).

Research from other countries has highlighted the positive effect of involving male partners in maternal health on women's utilization of reproductive health care services during pregnancy, delivery and in the postpartum period (Dudgeon \& Inhorn, 2004), including enhanced maternal access to antenatal and postnatal services (Redshaw \& Henderson, 2013; Tokhi et al., 2018; Van der Gaag et al., 2019), increased utilization of adequate ANC (Assaf \& Davis, 2018) and ANC during the first trimester (Mohammed et al., 2019). In addition, it has been observed that the participation of the male partner in ANC is associated with an increase in the number of deliveries taking place at a health facility (Chattopadhyay, 2012; Mangeni et al., 2012). Several systemic reviews have also reported that encouraging male partners to become involved in ANC is a promising intervention for obtaining improved maternal health outcomes, including improved utilization of prenatal and postnatal care (Aguiar \& Jennings, 2015; Tokhi et al., 2018).

Given the patriarchal and conservative social structure of Afghan society, with pre-defined responsibilities for men and women - including women being unable to act independently or needing a male companion to access health care services (Byrd \& Betron, 2015) - it is of fundamental importance to encourage male involvement in ANC to improve the access of women to maternal health care services. Involving male partners in their pregnant partners' utilization of reproductive health care services is, in fact, a new idea in developing countries, including Afghanistan, where traditionally maternal health is considered exclusively a woman's issue. Limited knowledge about ANC among women and their families, lack of financial support and transport problems have been highlighted as potential obstacles to the use of ANC services in Afghanistan (Rahmani \& Brekke, 2013). The involvement of male partners in maternal health issues can provide their pregnant partners with informational, financial, instrumental and emotional support (Story et al., 2012; Tokhi et al., 2018) and help them improve their health-seeking behaviours to tackle the demand-side barriers to accessing health services. Interventions that involve male partners have been linked to improved couple communication and shared decision-making (Hartmann et al., 2012), which are known to influence maternal health and care-seeking outcomes (Richards et al., 2011). Male partners have a crucial role to play in making decisions about health care in the family, which affects their pregnant partners' access to maternal health services (Dudgeon \& Inhorn, 2004). Men's potential influence on maternal health can be better conceptualized through the 'model of three delays' that lead to maternal deaths: delay in making the decision to seek care at a health facility, delay in reaching care and delay in the provision of care at the facility (Mahmood et al., 2018). Male participation, among other factors, can influence the first two delays. In some Afghan families, decisions about referring women to a 
health facility and arranging transport to it are made by the men of the family, or at least require their approval, since as a cultural norm most women depend on their husbands' permission as well as their income for accessing and/or receiving health care services.

International communities have put forward important strategies for decreasing maternal mortality, including improved pregnancy, delivery and postpartum care; better health facility services; greater education and heightened awareness levels (Shrestha et al., 2014). However, in addition, the involvement of male partners in reproductive health care is recommended as an essential intervention to improve maternal health outcomes (Varkey et al., 2004; WHO, 2015). Recognizing the dynamic role of male partners, the International Conference on Population and Development (ICPD) (United Nations, 2012) in Cairo and the $4^{\text {th }}$ World Conference on Women (United Nations, 1995) in Beijing formally acknowledged the importance of men's involvement in improving the sexual and reproductive health and rights of women, and countries were mandated to engage male partners in the implementation of sexual and reproductive health programmes. Particularly, in the ICPD, countries made a commitment to developing effective plans and strategies to involve men in all components of reproductive health care, including family planning, sexual health and maternal health care, which mainly include care during the antenatal, delivery and postnatal periods.

The 2015 WHO Recommendations on Health Promotion Interventions for Maternal and Newborn Health focused on interventions to promote active participation of men during pregnancy, childbirth and after birth, to facilitate and support improved maternal and newborn health outcomes. The interventions are recommended on the condition that women's choices and their autonomy in making decisions are respected (WHO, 2015).

The Afghanistan health sector stresses the need for the active involvement of men in reproductive health care to improve maternal and child health outcomes. The National Health Strategy 2016-2020 and National Reproductive, Maternal, Newborn, Child, and Adolescent Health Strategy 2017-2021 highlight the role of men in supporting women to increase their demand for, and their access to, quality health services (MoPH, 2016, 2017). Despite the potential benefit of involving men for improving maternal health outcomes, this has been neglected. Using data from the 2015 Afghanistan Demographic and Health Survey (AfDHS), the objective of this study was to examine the association between male attendance at ANC with their pregnant partners and the utilization of reproductive health care services by pregnant partners, with the aim of informing maternal health policy recommendations and intervention strategies in Afghanistan.

\section{Methods}

\section{Data}

The study was based on secondary data from the 2015 AfDHS. This was a nationally representative survey of the Afghan population that employed a two-stage stratified sampling design. The first stage involved selecting 950 clusters: 260 from urban and 690 from rural areas. The second stage involved systematic sampling of households within the clusters.

\section{Study sample}

Figure 1 shows the derivation of the study sample. Initially, men re-code and individual re-code datasets from the AfDHS were merged using key variables. The unit of analysis was a couple who met the inclusion criteria of being married and having at least one live birth in the previous 5 years. This allowed the selection of participants with recent experience of ANC and reduced the chances of recall bias. To make sure that the couples were reporting on the same child, only those who gave the same age for their last child and who had completed individual interviews, being questioned about childbirth and ANC for their last child, were included. Eligibility for inclusion also required that the women gave a history of at least one ANC visit during their last 


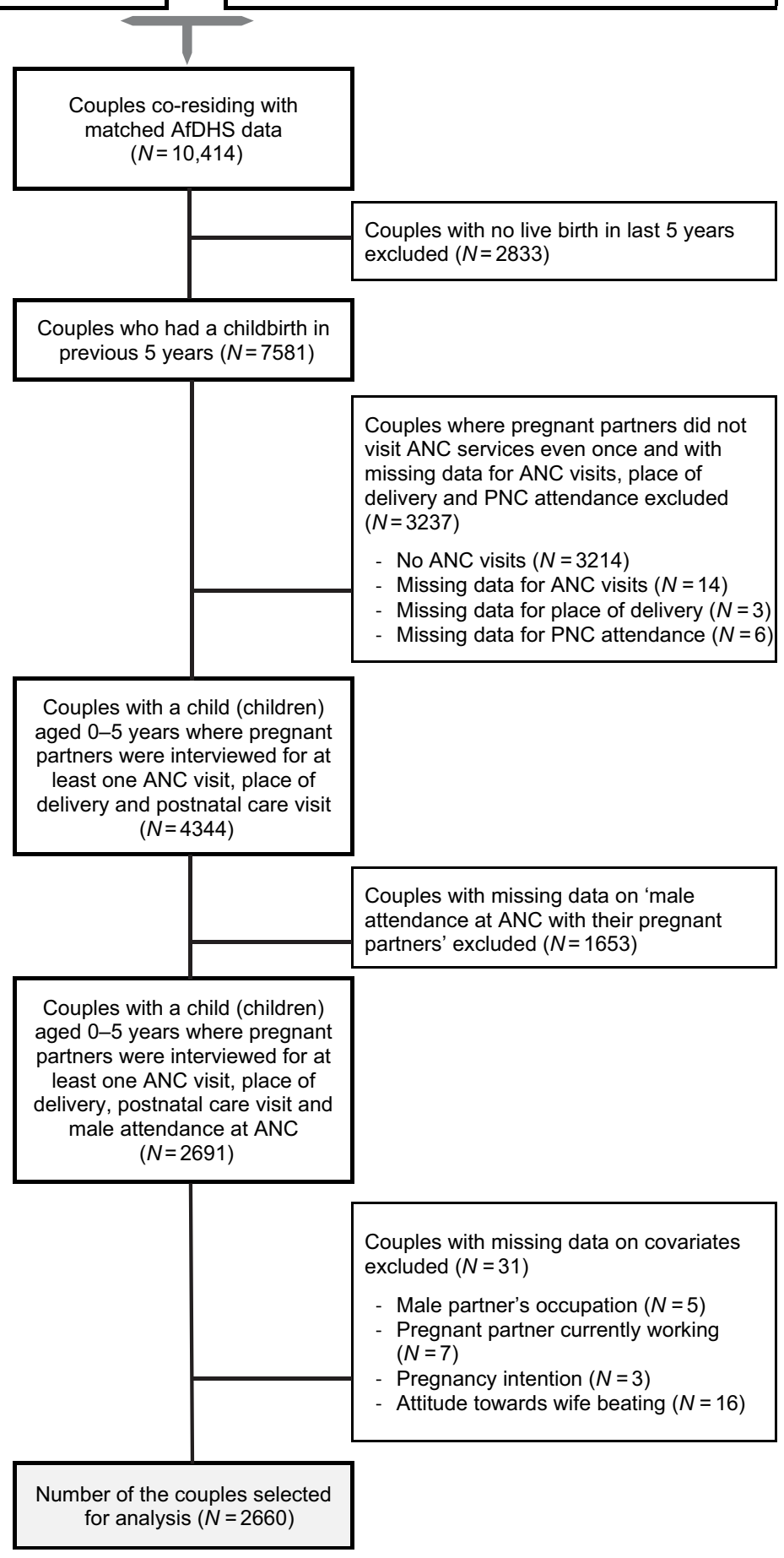

Figure 1. Flow chart of study data selection. 
pregnancy. The final weighted sample size was 2660 couples. To reduce the categories and simplify interpretation of the variables, the data were re-coded.

\section{Study variables}

Dependent variables

Six variables were developed as dependent variables to assess reproductive health care utilization: adequate utilization of ANC services (at least 4 visits), ANC utilization during the first trimester of pregnancy, urine testing during pregnancy, blood testing during pregnancy, institutional delivery and utilization of postnatal care. The number of ANC visits was assessed as a dichotomous categorical variable, created from continuous measurement of the frequency of ANC visits during pregnancy, as follows: 'adequate ANC' (four or more ANC visits) and 'inadequate ANC' (fewer than 4 visits), in line with the WHO gold standard definition (WHO, 2002, 2007). It is worth noting that the 2016 WHO Guidelines on Antenatal Care for a Positive Pregnancy Experience recommended at least eight ANC visits to reduce perinatal mortality and improve women's experience of care (WHO, 2016). As the study used 2015 AfDHS data, the previously recommended 4 visits was taken to define 'adequate ANC'.

'Utilization of ANC during the first trimester' was a binary variable constructed from the combined responses to the question on timing of the first ANC check-up. To assess rates of urine and blood testing during pregnancy, binary variables were constructed from the responses to the questions on whether the pregnant partners had undergone the tests. Place of delivery was assessed as a dichotomous variable: home delivery (when the pregnant partner gave birth to the baby in their home or another's home) and hospital (institutional) delivery (when the delivery took place at a public, private, non-governmental or other type of health facility). To assess the rate of attendance at postnatal check-ups, a binary variable was constructed from the combined responses to a question on health check-up visits after delivery.

\section{Explanatory variable}

The major explanatory variable was 'male attendance at ANC with their pregnant partners'. The variable 'men's participation during any ANC check-up' from the men's questionnaire was used to measure this. This variable was measured by the response to the question 'were you ever present during any of those antenatal check-ups?' and was coded 'yes' if the male partner accompanied his pregnant partner to the ANC facility, and 'no' if he did not. The AfDHS did not inquire if the male partner also participated in ANC consultations, and it is possible that some escorted their pregnant partners to the clinic but then went elsewhere and joined them again after the ANC visit.

\section{Covariates}

The covariates included in the study were linked to male attendance at ANC with their pregnant partners and reproductive health care service utilization in a theoretical and empirical manner. Male partner's age was classified into three age groups: 17-28, 29-35 and 36-49 years. Pregnant partner's age was categorized into: 16-24, 25-34 and 35-49 years. Both partners' education levels were classified in terms of the formal education system of Afghanistan: no education (0 years), primary education (1-6 years) and secondary education or higher (7 years or more). Male partner's occupation was categorized into six groups: professional/technical/managerial, clerical, agricultural, self-employed/employee, services/sales, skilled manual and unskilled manual. Pregnant partner's employment status was ranked according to whether she was working or not. Place of residence was categorized as rural or urban. The AfDHS wealth index was used as a proxy for the socioeconomic status of the household and was designated as 'poorest', 'middle' and 'richest' tertiles. The size of the household was classified based on the number of household members: $3-7,8-10$ or $11+$. Decision-making autonomy of pregnant partners was measured using four questions on these topics: who usually made family decisions about the pregnant partner's health care; large household purchases; visits to the pregnant partner's family and 
relatives; and the spending of the male partner's earnings. Response options included the pregnant partner alone, the pregnant partner jointly with her male partner, her male partner alone, and someone else. A composite score was generated giving a score of 1 to each decision that the pregnant partner made alone or jointly (and 0 otherwise) that yielded a score range of $0-4$, with 0 for having no decision-making autonomy in the family (i.e. decisions made solely by the male partner or someone else), 1 for participating in at least one of the four decisions, 2 for participating in two of the four decisions, 3 for participating in three of the four decisions and 4 for participating in all four decisions. The sex of the delivered child was categorized as female or male. A dichotomous variable was created to measure the pregnancy intentions for the last birth (intended: live birth wanted at time of conception; unintended: live birth wanted after conception or not wanted at all). Attitude towards wife beating was based on the question on whether 'wife beating' was considered acceptable under the following circumstances: if the wife goes out without telling her male partner; if she neglects the children; if she argues with the male partner; if she refuses to have sex with the male partner; or if she serves burnt food. It was categorized into the dichotomous responses 'yes' (if the respondent answered in the affirmative to at least one of these) indicating that wife beating was acceptable and 'no' if they answering in the negative to all of these.

\section{Statistical analysis}

Data were analysed using Stata software, version 15.1 (Stata Corp). Descriptive statistics were used to summarize the characteristics of the study participants. Several approaches were used to examine whether male attendance at ANC with their pregnant partners was associated with the outcome variables. First, bivariate associations were analysed of the rate of male attendance at ANC with their pregnant partners with the socio-demographic characteristics and outcome measures of reproductive health. Next, multivariate logistic regression analysis was performed to investigate the effects of the demographic and socioeconomic variables, maternal autonomy, pregnancy intention and male and pregnant partners' attitudes towards wife beating on the relationship between male attendance at ANC with their pregnant partners and utilization of reproductive health care by their pregnant partners. The model was applied with adjustment for demographic and socioeconomic factors. All analyses included survey sampling weights $(N=2660)$. Statistical testing was performed at a $95 \%$ level of significance, and a $p$-value of 0.05 was used as the cut-off point for significant association.

\section{Results}

\section{Description of study sample}

Figure 2 shows the rates of utilization of reproductive health care services by the pregnant partners. Only 30.5\% received adequate ANC, 48.8\% commenced ANC during the first trimester, $41.3 \%$ and $33.4 \%$, respectively, received urine and blood tests during pregnancy, $70.8 \%$ gave birth in an institution and $31.3 \%$ utilized postnatal care.

Table 1 describes the socio-demographic characteristics of the sample couples. The majority of male partners (36.9\%) were aged 17-28 years, and 39.9\% had no formal education. Almost half of the pregnant partners (48.6\%) were aged $25-34$ years, $79.2 \%$ had no education and $91 \%$ were unemployed. Nearly two-thirds of the couples (70.9\%) resided in rural areas, $37.7 \%$ were in the poorest wealth tertile and $36 \%$ lived in households with eleven or more household members. About one-third of the pregnant partners (34.7\%) had no decision-making autonomy, more than half of their delivered children (54.4\%) were male and $90 \%$ of their births were intended. The majority of male partners $(75.4 \%)$ and $86.9 \%$ of pregnant partners thought that wife beating was acceptable under at least one of the listed circumstances (see Table 1).

\section{Male attendance at ANC by socio-demographic characteristics of couples}

Table 2 shows the percentages of male attendance at ANC with their pregnant partners by demographic, socioeconomic, maternal autonomy, pregnancy intention and the couples' attitude 


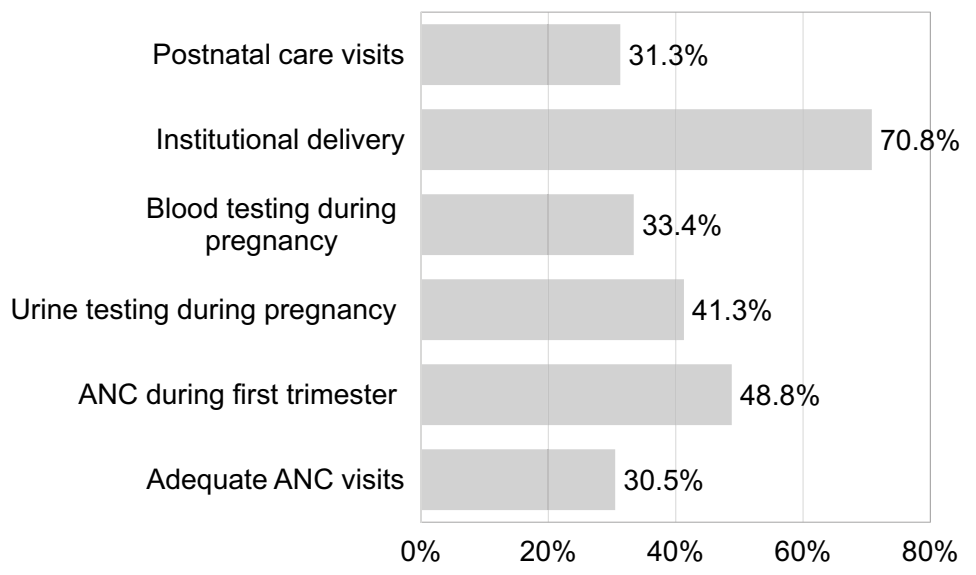

Figure 2. Utilization rate of reproductive health care services by pregnant partners.

related characteristics. Compared with male partners who did not accompany their pregnant partners to ANC facilities, those who attended at least one ANC visit with their pregnant partners were more educated, more likely to live in an urban area and more likely to have a professional job (clerk or higher). A higher rate of ANC attendance by pregnant partners was also identified among the unemployed pregnant partners and those who had more decision-making autonomy (involved in all four decisions compared with their counterparts).

Trends in associations of male attendance at ANC with their pregnant partners and other variables were also observed, including age of the male partner, number of household members, wealth status, pregnancy intention, sex of the child and attitude towards wife beating, although these were not statistically significant.

\section{Male attendance at ANC and utilization of reproductive health care services}

The percentage of male attendance at ANC at least once with their pregnant partners in relation to components of ANC utilized, as well as the tendency for institutional delivery and attendance at postnatal care, are presented in Table 3. A higher proportion of pregnant partners whose male partners accompanied them to at least one ANC visit had adequate ANC, received ANC during the first trimester, underwent urine and blood testing during pregnancy, gave birth in an institution and presented for postnatal care compared with those whose male partners never accompanied them to ANC visits.

Table 4 shows the factors associated with male attendance at ANC. Being an urban resident increased the likelihood of men's attendance at ANC by 1.49 times. On the other hand, it was lower for pregnant partners who were employed and for male partners with non-professional occupations (services/sales, skilled and unskilled manual).

\section{Results of logistic regression analysis}

Table 5 shows the results of multivariate analyses. After adjustments for socio-demographic factors, the odds of utilizing adequate ANC were 1.42 times higher for pregnant partners whose male partners attended at least one ANC visit than for those whose male partners did not attend any ANC visits with them $(\mathrm{AOR}=1.42,95 \% \mathrm{CI}$ : $1.18-1.71)$. Several of the factors, such as the pregnant partner's education level, place of residence and decision-making autonomy, positively influenced the rate of fulfilment of the criteria for adequate ANC. Pregnant partners who had higher education levels, resided in urban areas and had strong decision-making autonomy were more likely to have 'adequate ANC'. On the other hand, pregnant partners aged 25-34 years, living in households with eight or more members, who were rich, currently working and who said 
Table 1. Characteristics of couples selected for analysis, Afghanistan DHS 2015, N=2660

\begin{tabular}{|c|c|c|}
\hline Variable & $n$ & $\%$ \\
\hline \multicolumn{3}{|l|}{ Age of male partner (years) } \\
\hline $17-28$ & 981 & 36.9 \\
\hline 29-35 & 885 & 33.3 \\
\hline $36-49$ & 794 & 29.8 \\
\hline \multicolumn{3}{|l|}{ Age of pregnant partner (years) } \\
\hline $16-24$ & 882 & 33.2 \\
\hline $25-34$ & 1293 & 48.6 \\
\hline $35-49$ & 485 & 18.2 \\
\hline \multicolumn{3}{|l|}{ Education of male partner } \\
\hline No education & 1062 & 39.9 \\
\hline Primary & 534 & 20.1 \\
\hline Secondary & 763 & 28.7 \\
\hline Higher & 301 & 11.3 \\
\hline \multicolumn{3}{|l|}{ Education of pregnant partner } \\
\hline No education & 2107 & 79.2 \\
\hline Primary & 244 & 9.2 \\
\hline Secondary & 244 & 9.2 \\
\hline Higher & 65 & 2.4 \\
\hline \multicolumn{3}{|l|}{ Male partner's occupation } \\
\hline Professional/technical/managerial & 586 & 22.0 \\
\hline Clerical & 101 & 3.8 \\
\hline Agricultural/self-employed/employee & 589 & 22.1 \\
\hline Services/sales & 454 & 17.1 \\
\hline Skilled manual & 485 & 18.2 \\
\hline Unskilled manual & 445 & 16.8 \\
\hline \multicolumn{3}{|l|}{ Pregnant partner currently working } \\
\hline No & 2421 & 91.0 \\
\hline Yes & 239 & 9.0 \\
\hline \multicolumn{3}{|l|}{ Place of residence } \\
\hline Rural & 1886 & 70.9 \\
\hline Urban & 774 & 29.1 \\
\hline \multicolumn{3}{|l|}{ Wealth tertile } \\
\hline Poorest & 1003 & 37.7 \\
\hline Middle & 769 & 28.9 \\
\hline Richest & 888 & 33.4 \\
\hline
\end{tabular}


Table 1. (Continued)

\begin{tabular}{|c|c|c|}
\hline Variable & $n$ & $\%$ \\
\hline \multicolumn{3}{|c|}{ No. household members } \\
\hline $3-7$ & 895 & 33.7 \\
\hline $8-10$ & 807 & 30.3 \\
\hline $11+$ & 958 & 36.0 \\
\hline \multicolumn{3}{|c|}{ Maternal autonomy ${ }^{a}$} \\
\hline 0 & 924 & 34.7 \\
\hline 1 & 429 & 16.1 \\
\hline 2 & 269 & 10.1 \\
\hline 3 & 298 & 11.2 \\
\hline 4 & 740 & 27.9 \\
\hline \multicolumn{3}{|l|}{ Sex of child } \\
\hline Female & 1212 & 45.6 \\
\hline Male & 1448 & 54.4 \\
\hline \multicolumn{3}{|c|}{ Pregnancy intention ${ }^{b}$} \\
\hline Unintended & 267 & 10.0 \\
\hline Intended & 2393 & 90.0 \\
\hline \multicolumn{3}{|c|}{ Male partner justified wife beating ${ }^{c}$} \\
\hline No & 655 & 24.6 \\
\hline Yes & 2005 & 75.4 \\
\hline \multicolumn{3}{|c|}{ Pregnant partner justified wife beating ${ }^{c}$} \\
\hline No & 349 & 13.1 \\
\hline Yes & 2311 & 86.9 \\
\hline
\end{tabular}

${ }^{a}$ Number of family decisions pregnant partners made alone or jointly with male partners regarding: the pregnant partner's health care; large household purchases; visits to the female partner's family and relatives; and the spending of the male partner's earnings. 0 indicates having no decision-making autonomy in the family (i.e. decisions made solely by male partner or someone else), 1 indicates participating in at least one of the four decisions, 2 indicates participating in two of the four decisions, 3 indicates participating in three of the four decisions and 4 indicates participating in all four decisions.

bIntended: live birth wanted at the time of conception; unintended: live birth wanted after conception or not wanted at all.

${ }^{c}$ Beating justified if wife goes out without telling male partner; neglects the children; argues with male partner; refuses to have sex with male partner; or serves burnt food. 'No' indicates that wife beating is not acceptable under any of these circumstances.

that wife beating was acceptable under at least one of the circumstances listed were less likely to receive adequate ANC.

Male attendance at ANC with their pregnant partners was significantly associated with the commencement of ANC during the first trimester of pregnancy. The odds of this were 1.21 times higher for pregnant partners whose male partners attended at least one ANC visit with them than for those whose male partners never accompanied them for any ANC visit (AOR=1.21, 95\% CI: 1.03-1.42). Pregnant partners aged 25 years or over and who resided in urban areas were more likely to commence ANC in the first trimester than those in other categories. On the other hand, pregnant partners who were currently working, lived in households with 8-10 members and whose male partners were above 29 years old were less likely to commence ANC in the first trimester than their counterparts.

The multivariate analysis revealed no association between the rate of urine and blood testing performed during pregnancy and male attendance at ANC with their pregnant partners. 
Table 2. Percentage male attendance at ANC with pregnant partners by selected socio-demographic characteristics, Afghanistan DHS 2015, N=2660

\begin{tabular}{|c|c|c|c|}
\hline Variable & $\begin{array}{c}\text { Male partners } \\
\text { attending ANC }(\%) \\
(N=1846 ; 69.4 \%)\end{array}$ & $\begin{array}{l}\text { Male partners not } \\
\text { attending ANC }(\%) \\
(N=814 ; 30.6 \%)\end{array}$ & $p$-value \\
\hline Age of male partner (years) & & & ns \\
\hline $17-28$ & 63.0 & 37.0 & \\
\hline $29-35$ & 61.3 & 38.7 & \\
\hline $36-49$ & 62.1 & 37.9 & \\
\hline Age of pregnant partner (years) & & & ns \\
\hline $16-24$ & 63.1 & 36.9 & \\
\hline $25-34$ & 63.4 & 36.6 & \\
\hline $35-49$ & 57.2 & 42.8 & \\
\hline Education of male partner & & & 0.016 \\
\hline No education & 57.0 & 43.0 & \\
\hline Primary & 60.5 & 39.5 & \\
\hline Secondary & 65.6 & 34.4 & \\
\hline Higher & 77.6 & 22.4 & \\
\hline Education of pregnant partner & & & ns \\
\hline No education & 61.6 & 38.4 & \\
\hline Primary & 65.6 & 34.4 & \\
\hline Secondary & 59.5 & 40.5 & \\
\hline Higher & 77.7 & 22.3 & \\
\hline Male partner's occupation & & & 0.002 \\
\hline Professional/technical/managerial & 75.4 & 24.6 & \\
\hline Clerical & 77.8 & 22.2 & \\
\hline Agricultural/self-employed/employee & 61.6 & 38.4 & \\
\hline Services/sales & 61.1 & 38.9 & \\
\hline Skilled manual & 53.3 & 46.7 & \\
\hline Unskilled manual & 58.4 & 41.6 & \\
\hline Pregnant partner currently working & & & 0.002 \\
\hline No & 64.6 & 35.4 & \\
\hline Yes & 45.4 & 54.6 & \\
\hline Place of residence & & & 0.010 \\
\hline Rural & 59.7 & 40.3 & \\
\hline Urban & 70.1 & 29.9 & \\
\hline Wealth tertile & & & ns \\
\hline Poorest & 63.7 & 36.3 & \\
\hline Middle & 58.4 & 41.6 & \\
\hline Richest & 63.9 & 36.1 & \\
\hline
\end{tabular}


Table 2. (Continued)

\begin{tabular}{|c|c|c|c|}
\hline Variable & $\begin{array}{c}\text { Male partners } \\
\text { attending ANC }(\%) \\
(N=1846 ; 69.4 \%)\end{array}$ & $\begin{array}{l}\text { Male partners not } \\
\text { attending ANC }(\%) \\
(N=814 ; 30.6 \%)\end{array}$ & $p$-value \\
\hline No. household members & & & ns \\
\hline $3-7$ & 63.2 & 36.8 & \\
\hline $8-10$ & 60.6 & 39.4 & \\
\hline $11+$ & 62.4 & 37.6 & \\
\hline Maternal autonomy ${ }^{a}$ & & & $<0.001$ \\
\hline 0 & 67.5 & 32.5 & \\
\hline 1 & 55.4 & 44.6 & \\
\hline 2 & 45.9 & 54.1 & \\
\hline 3 & 62.1 & 37.9 & \\
\hline 4 & 71.6 & 28.4 & \\
\hline Sex of child & & & ns \\
\hline Female & 63.7 & 36.3 & \\
\hline Male & 60.8 & 39.2 & \\
\hline Pregnancy intention ${ }^{b}$ & & & ns \\
\hline Unintended & 54.8 & 45.2 & \\
\hline Intended & 63.0 & 37.0 & \\
\hline Male partner justified wife beating ${ }^{c}$ & & & ns \\
\hline No & 67.4 & 32.6 & \\
\hline Yes & 60.3 & 39.7 & \\
\hline Pregnant partner justified wife beating ${ }^{c}$ & & & ns \\
\hline No & 60.6 & 39.4 & \\
\hline Yes & 62.4 & 37.6 & \\
\hline
\end{tabular}

aNumber of family decisions pregnant partners made alone or jointly with male partners regarding: the pregnant partner's health care; large household purchases; visits to the female partner's family and relatives; and the spending of the male partner's earnings. 0 indicates having no decision-making autonomy in the family (i.e. decisions made solely by male partner or someone else), 1 indicates participating in at least one of the four decisions, 2 indicates participating in two of the four decisions, 3 indicates participating in three of the four decisions and 4 indicates participating in all four decisions.

bIntended: live birth wanted at the time of conception; unintended: live birth wanted after conception or not wanted at all.

'Beating justified if wife goes out without telling male partner; neglects the children; argues with male partner; refuses to have sex with male partner; or serves burnt food. ' $N$ ' indicates that wife beating is not acceptable under any of these circumstances.

$p<0.05$ indicates a significant difference; ' $n s$ ' indicates not significant.

Male attendance at ANC with their pregnant partners markedly increased the rate of institutional delivery $(\mathrm{AOR}=1.23,95 \% \mathrm{CI}: 1.03-1.47)$. Pregnant partners who were educated, resided in urban areas and who lived in households with eight or more members were more likely to give birth at a health facility. On the other hand, pregnant partners saying wife beating was acceptable under at least one of the circumstances listed were less likely to give birth at a hospital.

Male attendance at ANC with their pregnant partners was associated with a higher rate of utilization of postnatal care services $(\mathrm{AOR}=1.24,95 \% \mathrm{CI}$ : 1.04-1.47). The likelihood of utilizing postnatal care was higher in pregnant partners who were currently working and who resided in urban areas compared with other groups. On the other hand, pregnant partners with a secondary level of education and who had weak decision-making autonomy were less likely to receive postnatal care than their counterparts. 
Table 3. Percentage male attendance at ANC with their pregnant partners by utilization of reproductive health care services, Afghanistan DHS 2015, $N=2660$

\begin{tabular}{|c|c|c|c|c|}
\hline Variable & $n(\%)$ & $\begin{array}{c}\text { Male partners } \\
\text { attending ANC }(\%) \\
(N=1846 ; 69.4 \%)\end{array}$ & $\begin{array}{l}\text { Male partners not } \\
\text { attending ANC }(\%) \\
(N=814 ; 30.6 \%)\end{array}$ & $p$-value \\
\hline No. ANC visits & & & & 0.004 \\
\hline Inadequate & $1849(69.5)$ & 59.0 & 41.0 & \\
\hline Adequate & $811(30.5)$ & 69.9 & 30.1 & \\
\hline ANC visit in first trimester & & & & ns \\
\hline No & $1361(51.2)$ & 58.8 & 41.2 & \\
\hline Yes & $1299(48.8)$ & 65.7 & 34.3 & \\
\hline Urine test during pregnancy & & & & ns \\
\hline No & $1560(58.7)$ & 61.5 & 38.5 & \\
\hline Yes & $1099(41.3)$ & 63.1 & 36.9 & \\
\hline Blood test during pregnancy & & & & 0.007 \\
\hline No & $1767(66.6)$ & 59.5 & 40.5 & \\
\hline Yes & $887(33.4)$ & 68.8 & 31.2 & \\
\hline Place of delivery & & & & ns \\
\hline Home & $777(29.2)$ & 57.7 & 42.3 & \\
\hline Institution & $1883(70.8)$ & 64.1 & 35.9 & \\
\hline Postnatal care utilization & & & & ns \\
\hline No & $1828(68.7)$ & 60.3 & 39.7 & \\
\hline Yes & $832(31.3)$ & 66.2 & 33.8 & \\
\hline
\end{tabular}

$p<0.05$ indicates a significant difference; 'ns' indicates not significant.

\section{Discussion}

This study provides evidence on the influence of male attendance at ANC with their pregnant partners on health care measures for pregnancy, delivery and postpartum care in Afghanistan. The findings show that male attendance at ANC with their pregnant partners significantly increased pregnant partners' utilization of ANC services, commencing ANC during the first trimester, utilization of institutional delivery and postnatal check-up attendance.

The overall rate of male attendance at ANC in the study sample was high. Seven out of ten male partners whose pregnant partners needed ANC accompanied their partners to ANC services, which is comparable to figures reported in similar studies in Kenya (Mangeni et al., 2012), Myanmar (Wai et al., 2015) and Uganda (Tweheyo et al., 2010) of 68.4\%, 64.8\% and 65.4\%, respectively. However, it was higher than the rates reported in studies conducted in Nepal (39.3\%) (Bhatta, 2013), Ethiopia (19.7\%) (Asefa et al., 2014), Malawi (13.7\%) (Kalembo et al., 2013) and Nigeria (24\%) (Akinpelu \& Oluwaseyi, 2014), but lower than the rates reported in India (90.5\%) (Varkey et al., 2004) and Rwanda (86.8\%) (NISR, 2010). These discrepant rates could be attributable to socio-cultural differences across countries and differences in the periods when the studies were conducted. Thus, the findings of this study indicate that an encouraging platform is already in place for male partners' attendance at ANC with their pregnant partners in Afghanistan, which could serve as a catalyst to achieve full-scale male involvement in reproductive health care. 
Table 4. Association between male attendance at ANC with pregnant partners and selected socio-demographic variables, Afghanistan DHS 2015, $N=2660$

\begin{tabular}{|c|c|c|c|c|}
\hline Variable & Crude OR $(95 \% \mathrm{CI})$ & $p$-value & Adjusted OR $(95 \% \mathrm{Cl})$ & $p$-value \\
\hline \multicolumn{5}{|l|}{ Age of male partner (years) } \\
\hline $17-28$ (Ref.) & 1.00 & & 1.00 & \\
\hline $29-35$ & $0.93(0.64-1.35)$ & ns & $1.02(0.64-1.65)$ & ns \\
\hline $36-49$ & $0.96(0.66-1.40)$ & ns & $1.19(0.62-2.27)$ & ns \\
\hline \multicolumn{5}{|l|}{ Age of pregnant partner (years) } \\
\hline 16-24 (Ref.) & 1.00 & & 1.00 & \\
\hline $25-34$ & $1.01(0.71-1.44)$ & ns & $2.02(0.52-7.85)$ & ns \\
\hline $35-49$ & $0.78(0.51-1.20)$ & ns & $1.22(0.28-5.30)$ & ns \\
\hline \multicolumn{5}{|l|}{ Male partner's education level } \\
\hline No education (Ref.) & 1.00 & & 1.00 & \\
\hline Primary & $1.16(0.77-1.74)$ & ns & $1.09(0.74-1.59)$ & ns \\
\hline Secondary & $1.44(0.94-2.20)$ & ns & $1.34(0.92-1.94)$ & ns \\
\hline Higher & $2.62(1.68-4.08)$ & $<0.001$ & $1.57(0.92-2.69)$ & ns \\
\hline \multicolumn{5}{|l|}{ Male partner's occupation } \\
\hline Professional/technical/managerial (Ref.) & 1.00 & & 1.00 & \\
\hline Clerical & $1.15(0.50-2.64)$ & ns & $1.04(0.45-2.41)$ & ns \\
\hline Agricultural/self-employed/employee & $0.52(0.36-0.76)$ & 0.001 & $0.70(0.45-1.09)$ & ns \\
\hline Services/sales & $0.51(0.31-0.83)$ & 0.007 & $0.57(0.36-0.93)$ & 0.024 \\
\hline Skilled manual & $0.37(0.23-0.62)$ & $<0.001$ & $0.45(0.27-0.73)$ & 0.001 \\
\hline Unskilled manual & $0.46(0.31-0.68)$ & $<0.001$ & $0.55(0.35-0.85)$ & 0.008 \\
\hline \multicolumn{5}{|l|}{ Pregnant partner currently working } \\
\hline No (Ref.) & 1.00 & & 1.00 & \\
\hline Yes & $0.45(0.27-0.76)$ & 0.003 & $0.45(0.29-0.69)$ & $<0.001$ \\
\hline \multicolumn{5}{|l|}{ Place of residence } \\
\hline Rural (Ref.) & 1.00 & & 1.00 & \\
\hline Urban & $1.58(1.12-2.24)$ & 0.010 & $1.49(1.01-2.19)$ & 0.045 \\
\hline \multicolumn{5}{|l|}{ Wealth tertile } \\
\hline Poorest (Ref.) & 1.00 & & 1.00 & \\
\hline Middle & $0.80(0.54-1.18)$ & ns & $0.64(0.40-1.04)$ & ns \\
\hline Richest & $1.01(0.72-1.42)$ & ns & $1.50(0.36-6.12)$ & ns \\
\hline \multicolumn{5}{|l|}{ No. household members } \\
\hline 3-7 (Ref.) & 1.00 & & 1.00 & \\
\hline $8-10$ & $0.89(0.62-1.28)$ & ns & $0.88(0.63-1.24)$ & ns \\
\hline $11+$ & $0.97(0.66-1.42)$ & ns & $0.95(0.67-1.33)$ & ns \\
\hline \multicolumn{5}{|l|}{ Sex of child } \\
\hline Female (Ref.) & 1.00 & & 1.00 & \\
\hline Male & $0.88(0.64-1.21)$ & ns & $0.88(0.66-1.17)$ & ns \\
\hline
\end{tabular}


Table 4. (Continued)

\begin{tabular}{|c|c|c|c|c|}
\hline Variable & Crude OR $(95 \% \mathrm{Cl})$ & $p$-value & Adjusted OR $(95 \% \mathrm{Cl})$ & $p$-value \\
\hline \multicolumn{5}{|l|}{ Pregnancy intention $^{a}$} \\
\hline Unintended (Ref.) & 1.00 & & 1.00 & \\
\hline Intended & $1.40(0.81-2.42)$ & ns & $1.31(0.83-2.07)$ & ns \\
\hline \multicolumn{5}{|c|}{ Male partner justified wife beating ${ }^{b}$} \\
\hline No (Ref.) & 1.00 & & 1.00 & \\
\hline Yes & $0.73(0.52-1.04)$ & ns & $0.83(0.60-1.15)$ & ns \\
\hline
\end{tabular}

antended: live birth wanted at the time of conception; unintended: live birth wanted after conception or not wanted at all.

${ }^{b}$ Beating justified if wife goes out without telling male partner; neglects the children; argues with male partner; refuses to have sex with male partner; or serves burnt food. 'No' indicates that wife beating is not acceptable under any of these circumstances.

$\mathrm{OR}=$ Odds Ratio; $\mathrm{Cl}=$ Confidence Interval.

$p<0.05$ indicates a significant difference; ' $n s$ ' indicates not significant.

The study found independent associations between male attendance at ANC with their pregnant partners and reproductive health service utilization not only in terms of ANC visits, but also rate of institutional deliveries and postnatal check-ups. Among the reproductive health care utilization outcomes, that which was most influenced by men's attendance at ANC with their pregnant partners was adequate utilization (four or more visits) of ANC facilities. Male attendance at ANC with their pregnant partners increased the likelihood of pregnant partners receiving adequate ANC, in compliance with WHO guidelines; pregnant partners whose partners accompanied them for at least one ANC visit were more likely to sufficiently utilize ANC services than those whose male partners did not accompany them. This could imply that men who accompanied their pregnant partners for their ANC visits had greater knowledge about the importance of ANC. Similar findings have been reported in a previous study based on data obtained from the most recent DHS survey conducted in 33 countries (Assaf \& Davis, 2018), which showed that pregnant partners whose male partners were present during at least one ANC visit had a higher likelihood of attending at least four ANC visits compared with those whose male partners were not present during any of their ANC visits. However, a study conducted in Vietnam found no correlation between male attendance at ANC with their pregnant partners and satisfactory utilization (four or more visits) of ANC services (Ha et al., 2015).

Consistent with the results of a community-based couple study conducted in Ethiopia (Mohammed et al., 2019), the current study also found that pregnant partners who attended ANC with their spouses were more likely to commence their ANC visits in the first trimester of pregnancy. It is important for pregnant partners to seek care from an early stage of pregnancy to ensure care of their own health and that of their babies, and that any potential risks are identified in a timely manner. Pregnant partner's age and area of residence were significant factors influencing early seeking of ANC: pregnant partners aged 25 years or over and those residing in urban areas commenced care earlier than those who were younger and who lived in rural areas. This could be because older women have greater awareness of the need for care during pregnancy and understand the importance of receiving health consultations for reproductive health concerns early so as to prevent/reduce possible risks, even at an early stage.

No significant association was found between male attendance at ANC with their pregnant partners and the rate of performance of blood and urine tests during pregnancy. However, a study conducted in Ethiopia demonstrated a positive association and revealed that pregnant partners who attended ANC with their male partners were more likely to receive such tests during pregnancy than those who attended ANC without their male partners (Forbes et al., 2018). Therefore, further studies are needed to investigate this association in Afghanistan. 
Table 5. Association between reproductive health care utilization and male attendance at ANC with their pregnant partners adjusted by other variables, Afghanistan DHS $2015, \mathrm{~N}=2660$

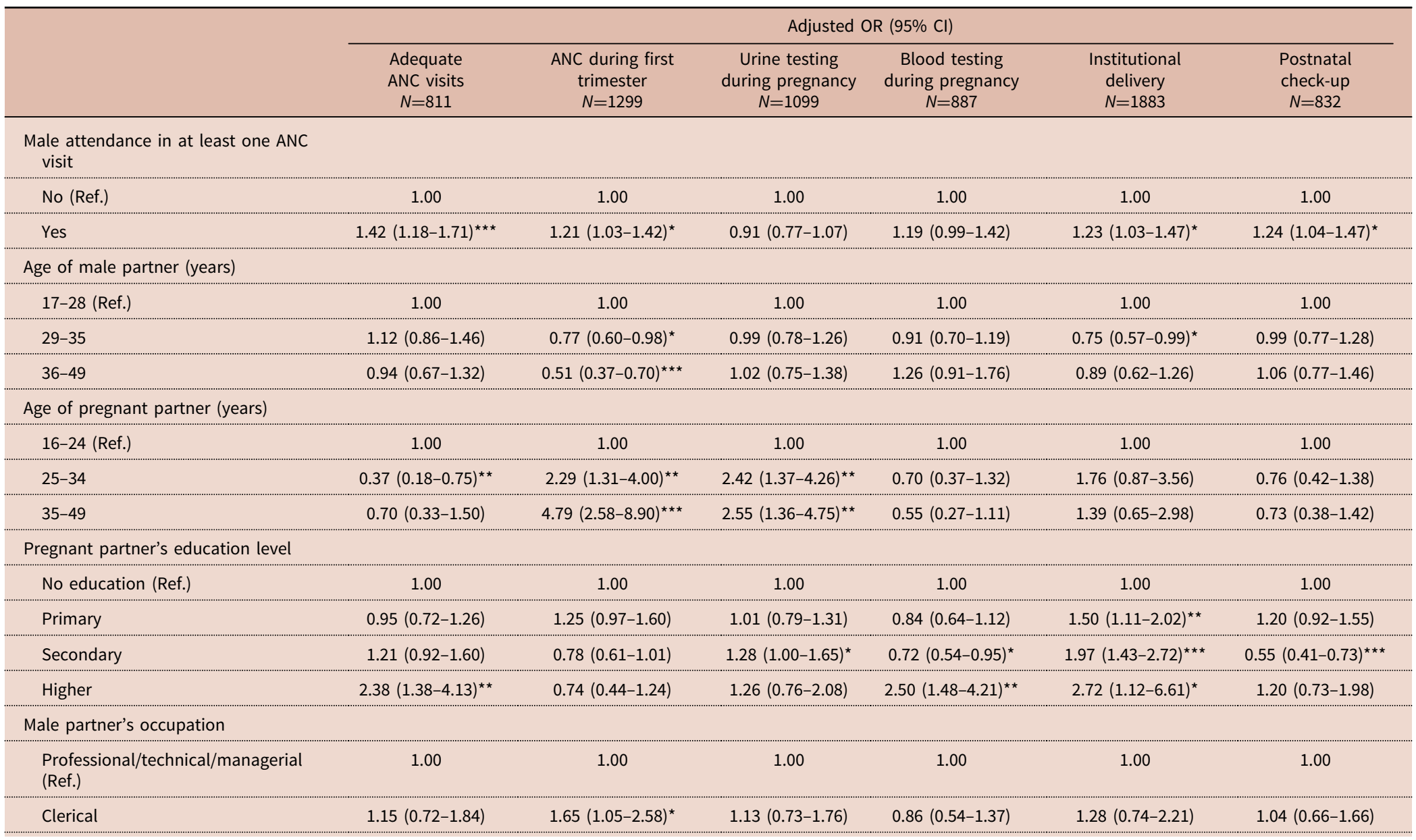


Table 5. (Continued)

\begin{tabular}{|c|c|c|c|c|c|c|}
\hline & \multicolumn{6}{|c|}{ Adjusted OR $(95 \% \mathrm{Cl})$} \\
\hline & $\begin{array}{l}\text { Adequate } \\
\text { ANC visits } \\
N=811\end{array}$ & $\begin{array}{l}\text { ANC during first } \\
\text { trimester } \\
N=1299\end{array}$ & $\begin{array}{c}\text { Urine testing } \\
\text { during pregnancy } \\
\qquad=1099\end{array}$ & $\begin{array}{c}\text { Blood testing } \\
\text { during pregnancy } \\
N=887\end{array}$ & $\begin{array}{c}\text { Institutional } \\
\text { delivery } \\
N=1883\end{array}$ & $\begin{array}{l}\text { Postnatal } \\
\text { check-up } \\
N=832\end{array}$ \\
\hline Agricultural/self-employed/employee & $0.53(0.40-0.69)^{\star \star \star}$ & $1.08(0.84-1.37)$ & $0.83(0.65-1.07)$ & $0.39(0.30-0.51)^{\star \star \star}$ & $0.51(0.39-0.66)^{\star \star \star}$ & $1.03(0.80-1.32)$ \\
\hline Services/sales & $0.56(0.42-0.75)^{\star \star \star}$ & $1.50(1.15-1.94)^{\star \star}$ & $0.89(0.69-1.16)$ & $0.59(0.45-0.77)^{\star \star \star}$ & $1.09(0.81-1.49)$ & $0.86(0.65-1.13)$ \\
\hline Skilled manual & $0.69(0.53-0.90)^{\star \star}$ & $0.81(0.63-1.04)$ & $1.05(0.82-1.34)$ & $0.48(0.37-0.62)^{\star \star \star}$ & $1.47(1.10-1.97)^{\star}$ & $0.88(0.68-1.14)$ \\
\hline Unskilled manual & $0.73(0.55-0.97)^{\star}$ & $1.25(0.96-1.62)$ & $1.07(0.83-1.40)$ & $0.71(0.54-0.93)^{\star}$ & $0.67(0.50-0.90)^{\star \star}$ & $0.89(0.67-1.17)$ \\
\hline \multicolumn{7}{|l|}{ Pregnant partner currently working } \\
\hline No (Ref.) & 1.00 & 1.00 & 1.00 & 1.00 & 1.00 & 1.00 \\
\hline Yes & $0.65(0.49-0.86)^{\star \star}$ & $0.54(0.42-0.69)^{\star \star \star}$ & $0.58 \underset{\star \star \star}{(0.45-0.74)}$ & $0.79(0.60-1.04)$ & $1.05(0.81-1.37)$ & $1.83(1.44-2.33)^{\star \star \star}$ \\
\hline \multicolumn{7}{|l|}{ Place of residence } \\
\hline Rural (Ref.) & 1.00 & 1.00 & 1.00 & 1.00 & 1.00 & 1.00 \\
\hline Urban & $2.38(1.95-2.90)^{\star \star \star}$ & $1.95(1.61-2.37)^{\star \star \star}$ & $1.76 \underset{\star \star \star}{(1.46-2.13)}$ & $1.68(1.38-2.05)^{\star \star \star}$ & $3.26(2.51-4.23)^{\star \star \star}$ & $1.24(1.02-1.52)^{*}$ \\
\hline \multicolumn{7}{|l|}{ Wealth tertile } \\
\hline Poorest (Ref.) & 1.00 & 1.00 & 1.00 & 1.00 & 1.00 & 1.00 \\
\hline Middle & $1.02(0.78-1.34)$ & $0.80(0.62-1.01)$ & $1.16(0.91-1.47)$ & $0.89(0.69-1.16)$ & $0.98(0.75-1.29)$ & $1.03(0.80-1.33)$ \\
\hline Richest & $0.36(0.17-0.77)^{\star \star}$ & $1.65(0.90-3.04)$ & $2.55(1.37-4.72)^{\star \star}$ & $0.68(0.34-1.34)$ & $1.43(0.68-3.03)$ & $0.86(0.45-1.64)$ \\
\hline \multicolumn{7}{|l|}{ No. household members } \\
\hline 3-7 (Ref.) & 1.00 & 1.00 & 1.00 & 1.00 & 1.00 & 1.00 \\
\hline $8-10$ & $0.58(0.47-0.73)^{\star \star \star}$ & $0.66(0.54-0.80)^{\star * *}$ & $1.23(1.00-1.50)^{\star}$ & $0.99(0.80-1.24)$ & $1.58(1.27-1.97)^{\star \star \star}$ & $1.08(0.88-1.34)$ \\
\hline $11+$ & $0.55(0.44-0.67)^{\star \star \star}$ & $0.90(0.75-1.09)$ & $1.13(0.94-1.37)$ & $1.02(0.83-1.26)$ & $1.78(1.44-2.20)^{\star \star \star}$ & $1.08(0.88-1.31)$ \\
\hline \multicolumn{7}{|l|}{ Maternal autonomy ${ }^{a}$} \\
\hline 0 (Ref.) & 1.00 & 1.00 & 1.00 & 1.00 & 1.00 & 1.00 \\
\hline 1 & $1.01(0.77-1.33)$ & $1.00(0.79-1.26)$ & $0.84(0.66-1.06)$ & $0.67(0.51-0.87)^{\star \star}$ & $0.98(0.76-1.27)$ & $0.77(0.60-0.98)^{\star}$ \\
\hline
\end{tabular}


Table 5. (Continued)

\begin{tabular}{|c|c|c|c|c|c|c|}
\hline & \multicolumn{6}{|c|}{ Adjusted OR $(95 \% \mathrm{CI})$} \\
\hline & $\begin{array}{c}\text { Adequate } \\
\text { ANC visits } \\
N=811\end{array}$ & $\begin{array}{c}\text { ANC during first } \\
\text { trimester } \\
N=1299\end{array}$ & $\begin{array}{l}\text { Urine testing } \\
\text { during pregnancy } \\
\qquad N=1099\end{array}$ & $\begin{array}{c}\text { Blood testing } \\
\text { during pregnancy } \\
N=887\end{array}$ & $\begin{array}{c}\text { Institutional } \\
\text { delivery } \\
N=1883\end{array}$ & $\begin{array}{c}\text { Postnatal } \\
\text { check-up } \\
N=832\end{array}$ \\
\hline 2 & $1.25(0.93-1.66)$ & $0.99(0.77-1.28)$ & $0.82(0.63-1.06)$ & $0.69(0.52-0.93)^{\star}$ & $0.84(0.63-1.11)$ & $0.57(0.44-0.78)^{\star \star \star}$ \\
\hline 3 & $1.23(0.94-1.61)$ & $0.95(0.75-1.22)$ & $1.25(0.98-1.59)$ & $0.96(0.74-1.25)$ & $1.29(0.97-1.71)$ & $1.00(0.78-1.28)$ \\
\hline 4 & $1.72(1.35-2.20)^{\star \star \star}$ & $1.05(0.84-1.30)$ & $1.31(1.05-1.63)^{\star}$ & $1.37(1.09-1.73)^{\star \star}$ & $1.14(0.90-1.46)$ & $1.05(0.84-1.31)$ \\
\hline \multicolumn{7}{|l|}{ Sex of child } \\
\hline Female (Ref.) & 1.00 & 1.00 & 1.00 & 1.00 & 1.00 & 1.00 \\
\hline Male & $1.15(0.97-1.36)$ & $1.29(1.11-1.50)^{\star \star}$ & $0.86(0.74-1.00)$ & $0.99(0.84-1.17)$ & $1.20(1.01-1.42)^{\star}$ & $1.08(0.92-1.27)$ \\
\hline \multicolumn{7}{|l|}{ Pregnancy intention ${ }^{\mathrm{b}}$} \\
\hline Unintended (Ref.) & 1.00 & 1.00 & 1.00 & 1.00 & 1.00 & 1.00 \\
\hline Intended & $0.92(0.69-1.23)$ & $1.00(0.77-1.29)$ & $1.35(1.04-1.76)^{\star}$ & $1.40(1.04-1.88)^{*}$ & $0.97(0.72-1.31)$ & $0.82(0.63-1.07)$ \\
\hline \multicolumn{7}{|c|}{ Pregnant partner justified wife beating ${ }^{c}$} \\
\hline No (Ref.) & 1.00 & 1.00 & 1.00 & 1.00 & 1.00 & 1.00 \\
\hline Yes & $0.62(0.48-0.79)^{\star \star \star}$ & $0.92(0.73-1.16)$ & $0.70(0.56-0.88)^{\star \star}$ & $0.71(0.56-0.91)^{\star \star}$ & $0.65(0.49-0.87)^{\star *}$ & $0.97(0.76-1.24)$ \\
\hline
\end{tabular}

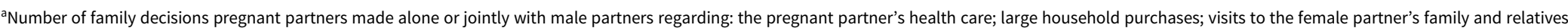

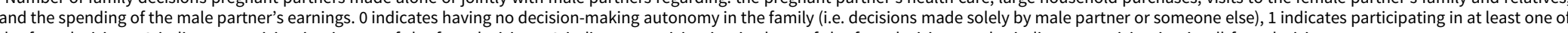
the four decisions, 2 indicates participating in two of the four decisions, 3 indicates participating in three of the four decisions and 4 indicates participating in all four decisions.

Intended: live birth wanted at the time of conception; unintended: live birth wanted after conception or not wanted at all.


acceptable at all of these circumstances.

${ }^{\star \star *} p<0.001 ;{ }^{\star \star} p<0.01 ;{ }^{\star} p<0.05$. 
The study also showed that male partners' presence during ANC consultations improved institutional delivery rates. Improved rates of these care-seeking behaviours could have resulted from the pregnant partners having felt more empowered by their partner's support to make decisions to meet their own health care needs and those of their infants. These findings are consistent with reports from prior studies that showed increased rates of health facility births in couples with higher overall involvement of their male partners (Chattopadhyay, 2012; Mangeni et al., 2012; Kalembo et al., 2013; Mohammed et al., 2019). In contrast, a study conducted in Nepal found that pregnant partners receiving ANC education along with their male partners had no effect on their place of delivery (Mullany et al., 2007).

Pregnant partners who were accompanied by their male partners to ANC were more likely to utilize PNC services. A randomized controlled trial on the impact of the male partner's involvement in ANC in Nepal reported a similar finding (Mullany et al., 2007), as did prior studies conducted in other developing countries (Mon et al., 2018; Rahman et al., 2018). Given such positive effects, encouraging male involvement in ANC programmes may be an effective strategy for improving pregnant partners' utilization of reproductive health care services.

The concept of male involvement in reproductive health care is broad and multifaceted and could include a wide range of ideas, from the male partners physically attending a health facility-based activity with their pregnant partners to provision of emotional and instrumental support for pregnant partners' health from the start of pregnancy to the end of the postnatal period. In a nutshell, there is no specific operational definition of what might constitute 'male involvement' or any uniform method/standardized indicator to measure it. Some studies use the terms 'male involvement', 'men's attendance', 'men's accompaniment', 'male participation' and 'male engagement' interchangeably when it comes to reproductive health, depending on the settings. In the context of Afghanistan, male participation in ANC denotes male partners accompanying their pregnant partners to ANC facilities. Some of the male partners could have escorted their pregnant partners to the clinic and then gone elsewhere to then return again to fetch their partners after the ANC visit. Some studies used certain proxy indicators to rate male involvement, including accompanying the pregnant partner to the ANC visit at least two times, having knowledge of the danger signs of pregnancy, having knowledge about the number of ANC visits representing adequate ANC, being present during childbirth, giving financial support, identifying the health facility for delivery and arranging transport (Matiang'i et al., 2014). The term 'male involvement' is typically used to indicate that male partners have knowledge about, and participate in, ANC. It can be directed towards participatory roles such as acting as partners and making joint decisions that will improve the health outcomes of women and children. Involvement of men is also linked with being accessible, supportive, patient and kind to their pregnant partners and understanding pregnancy-related issues (Alio et al., 2013). It may be concluded that more sophisticated measures of 'male involvement' are required that can fit various research contexts.

The findings of this study suggest that education has a crucial role to play in ensuring ANC attendance by male partners in maternal health care in Afghanistan. Male partners with higher levels of education were found to be more likely to accompany their pregnant partners to ANC than their peers with lower levels of, or no, education. In Afghanistan, educated men benefit more from health promotion programmes that cover awareness-raising and behavioural change interventions to foster improved maternal and neonatal health. These programmes can help with a variety of interventions - from better understanding of maternal health care services to recognizing the need for the involvement of male partners in their pregnant partners' reproductive health, including ANC visits. It is also likely that educated men make informed decisions about seeking care, while discarding negative attitudes and harmful cultural beliefs and practices. It is also worth noting that men with higher levels of education may have formal employment with better salaries, which enable them to bear the health care-related costs of their pregnant partners. On the other hand, uneducated men or those who have little education are perceived to hold onto outdated cultural traditions/beliefs and put more constraints on their pregnant partners' mobility and 
decision-making, which can negatively affect male attendance at ANC. This finding is in line with studies conducted in different countries that showed increased likelihood of involvement of the male partner in maternal health care in association with obtaining formal education (Byamugisha et al., 2010; Shahjahan et al., 2013). In this context, it is noteworthy that studies conducted in Nepal and Bangladesh have revealed that no education or low level of education increased the odds of active involvement of men in reproductive health issues (Bhatta, 2013; Bishwajit et al., 2017).

Men's occupation was found to influence their attendance at ANC. Those with formal occupations (professional, technical, managerial or clerical) have higher levels of education and better information about maternal health issues. Given the prevailing situation in Afghanistan, men who are informally employed, particularly self-employed or daily-wage employees, spend most of their time at their workplaces and lack the time to attend ANC activities with their spouses during the working hours of health facilities. This is concordant with a study conducted in Nepal, which reported that men with formal occupations were more likely to accompany their pregnant partners to ANC visits (Bhatta, 2013). The findings of the current study are in contrast to those of a study conducted in Kenya, which reported that the majority of employed men who escorted their spouses to ANC did not have formal jobs (Ongeso \& Okoth, 2018). As for pregnant partners' employment, it was found that pregnant partners who were not employed were more likely to get their male partners involved in ANC compared with those who were employed. However, a study conducted in Ethiopia indicated that housewives were less likely to be escorted by their spouses to ANC visits (Asefa et al., 2014). Within the context of Afghanistan, where the majority of men have informal employment, there is a critical need for important strategies to engage informal employees in maternal health care services.

A higher proportion of male partners living in urban areas escorted their pregnant partners to ANC visits than those living in rural areas. Urban residents in Afghanistan were more likely to utilize maternal health services (MoPH \& KIT, 2018). This could be because people residing in urban areas have more knowledge about the importance of pregnant partners' reproductive health care, have a higher socioeconomic status, have greater exposure to the media and enjoy access to well-equipped health care services, all of which are likely to improve health care utilization.

Although males in urban areas are pre-occupied with formal jobs, they can take some time off work to accompany their wives for ANC visits. Consistently, higher levels of education and raised awareness of health issues among urban dwellers could enable men to recognize their responsibilities towards supporting their partners in accessing health care and shed the misconception that reproductive health care is only a concern of women. Urban males are less likely to feel ashamed to be involved in the utilization of health care services for their pregnant partners than rural men, who often think it is below their dignity to walk alongside their pregnant partners. This result is in line with studies conducted in Ethiopia, which reported a higher likelihood of male attendance at ANC with their pregnant partners in urban areas (Asefa et al., 2014; Kassahun et al., 2018). In contrast, a study in Bangladesh showed opposite results - that men residing in urban areas had lower odds of accompanying their pregnant partners for ANC visits compared with those living in rural areas (Bishwajit et al., 2017). This suggests that programmes on male involvement should focus on rural residents to improve male attendance at ANC in Afghanistan.

Women's empowerment was also a factor that significantly increased a women's likelihood of being accompanied by their male partners to receive ANC. Thus empowering women could be a promising strategy for enhancing their male partners' involvement in their ANC. The findings of this study are consistent with evidence from a study conducted in selected African countries, which reported that women with higher empowerment were more likely to have their male partners accompany them to ANC compared with women with lower degrees of empowerment in Burkina Faso and Uganda, but the opposite was reported in Malawi (Jennings et al., 2014). Conversely, studies conducted in Nepal have revealed that higher decision-making autonomy of women is associated with lower rates of male participation in maternal health issues (Mullany et al., 2005; Thapa \& Niehof, 2013). 
In conclusion, the study findings provide evidence that, in Afghanistan, male attendance at ANC with their pregnant partners is associated with those partners receiving not only adequate and timely antenatal care - four or more ANC visits and ANC during the first trimester - but also increases their likelihood of giving birth at a health facility and utilizing postnatal care. Therefore, it is recommended that the Ministry of Public Health design policies and behaviour change strategies that influence the involvement of male partners in ANC to improve reproductive health outcomes and ultimately contribute to a reduction in maternal and childhood mortality and morbidity in Afghanistan, where pregnant mothers and children are still dying at alarming rates. On balance, the findings demonstrated a good proportion of male attendance at ANC in Afghanistan. Public health managers should put effort into designing programmes that target wider inclusion of male partners in ANC consultations to support the existing encouraging platform and increase reproductive health care utilization. The findings could be applied to implement community-wide awareness and education programmes for male partners to further sensitize them to the benefits of their involvement in ensuring and supporting their pregnant partners in health seeking behaviours. Additional qualitative research is needed to obtain a more in-depth understanding of the attitudes and perceptions of men, women, and health care providers towards male involvement in reproductive health issues in Afghanistan. Qualitative measures could also assist in identifying the cultural dimensions, potential barriers/facilitators and contributory factors to effect changes in what is traditionally viewed as a woman's concern alone.

\section{Study strengths and limitations}

The study had some limitations. The cross-sectional nature of the DHS data could have introduced reporting bias arising from socially desirable responses of the study participants, particularly regarding male attendance at ANC with their pregnant partners. It also did not allow collection of information about why many males did not attend ANC with their pregnant partners; a male partner's absence from home may be the reason, rather than that he was unwilling to attend or was uninterested. The AfDHS did not explicitly inquire whether male partners also participated in ANC consultations along with their pregnant partners. This would help provide clear understanding of male partners present during ANC consultations and male partners only escorting their pregnant partners to the clinic for the ANC visits and did not attend the consultations. Reverse causation may be also a possible alternative explanation for associations between the exposure and outcome measures. Ultimately, this study only targeted attendees of ANC clinics and excluded pregnant partners who had never visited an ANC clinic; thus, the data did not represent all pregnant partners in the Afghanistan Demographic and Health Survey.

Funding. This work was partly supported by a Grant-in-Aid for Scientific Study of Japan Society for the Promotion of Science (17H02164).

Conflicts of Interest. The authors declare that they had no conflicts of interest.

Ethical Approval. This study used microdata from the 2015 Afghanistan Demographic and Health Survey (DHS 2015/AfDHS 2015), which was conducted with ethical approval from the Central Statistics Organization (CSO) and the Ministry of Public Health (MoPH) of Government of Islamic Republic of Afghanistan. The authors obtained the microdata without personal identification information on $31^{\text {st }}$ October 2018.

\section{References}

Aguiar C and Jennings L (2015) Impact of male partner antenatal accompaniment on perinatal health outcomes in developing countries: a systematic literature review. Maternal and Child Health Journal 19(9), 2012-2019.

Akinpelu AO and Oluwaseyi OI (2014) Attitude and practice of males towards antenatal care in Saki West Local Government Area of Oyo State, Nigeria. Advances in Life Science and Technology 22, 1-6. 
Alio AP, Lewis CA, Scarborough K, Harris K and Fiscella K (2013) A community perspective on the role of fathers during pregnancy: a qualitative study. BMC Pregnancy and Childbirth 13(1), 60.

Alkema L, Chou D, Hogan D, Zhang S, Moller AB et al. (2016) Global, regional, and national levels and trends in maternal mortality between 1990 and 2015, with scenario-based projections to 2030: a systematic analysis by the UN Maternal Mortality Estimation Inter-Agency Group. The Lancet 387(10017), 462-474.

Asefa F, Geleto A and Dessie Y (2014) Male partners involvement in maternal ANC care: the view of women attending ANC in Hararipublic health institutions, Eastern Ethiopia. Science Journal of Public Health 2(3), 182-188.

Assaf S and Davis LM (2018) Does men's involvement improve the health outcomes of their partners and children? DHS Analytical Studies No. 64. ICF, Rockville, MD, USA. URL: http://dhsprogram.com/pubs/pdf/AS64/AS64.pdf (accessed July 2019).

Bhatta DN (2013) Involvement of males in antenatal care, birth preparedness, exclusive breast feeding and immunizations for children in Kathmandu, Nepal. BMC Pregnancy and Childbirth 13(1), 14.

Bishwajit G, Tang S, Yaya S, Ide S, Fu H et al. (2017) Factors associated with male involvement in reproductive care in Bangladesh. BMC Public Health 17(1), 1-8.

Byamugisha R, Tumwine JK, Semiyaga N and Tylleskär T (2010) Determinants of male involvement in the prevention of mother-to-child transmission of HIV programme in Eastern Uganda: a cross-sectional survey. Reproductive Health 7(1), 12

Byrd D and Betron M (2015) Integrating Gender From Start to Finish, Inside and Outside: Lessons from Afghanistan's Health Services Support Project. URL: https://www.jhpiego.org/wp-content/uploads/2015/08/Afghanistan-Case-Study.pdf (accessed May 2019)

Chattopadhyay A (2012) Men in maternal care: evidence from India. Journal of Biosocial Science 44(2), 129-153.

CSO, MoPH and ICF (2016) Afghanistan Demographic and Health Survey: 2015. Central Statistics Organization, Ministry of Public Health, Kabul, Afghanistan, and ICF International, Rockville, MD, USA. URL: https://dhsprogram.com/pubs/pdf/ FR323/FR323.pdf (accessed May 2019).

Dudgeon MR and Inhorn MC (2004) Men's influences on women's reproductive health: medical anthropological perspectives. Social Science \& Medicine 59(7), 1379-1395.

Forbes F, Wynter K, Wade C, Zeleke BM and Fisher J (2018) Male partner attendance at antenatal care and adherence to antenatal care guidelines: secondary analysis of 2011 Ethiopian Demographic and Health Survey data. BMC Pregnancy and Childbirth 18(1), 145.

Ha BT, Tac PV, Duc DM, Duong DT and Thi LM (2015) Factors associated with four or more antenatal care services among pregnant women: a cross-sectional survey in eight South Central Coast provinces of Vietnam. International Journal of Women's Health 7, 699-706.

Hartmann M, Gilles K, Shattuck D, Kerner B and Guest G (2012) Changes in couples' communication as a result of a maleinvolvement family planning intervention. Journal of Health Communication 17(7), 802-819.

Jennings L, Na M, Cherewick M, Hindin M, Mullany B and Ahmed S (2014) Women's empowerment and male involvement in antenatal care: analyses of Demographic and Health Surveys (DHS) in selected African countries. BMC Pregnancy and Childbirth 14(1), 1-11

Kalembo FW, Zgambo M, Mulaga AN, Yukai D and Ahmed NI (2013) Association between male partner involvement and the uptake of prevention of mother-to-child transmission of HIV (PMTCT) interventions in Mwanza District, Malawi: a retrospective cohort study. PLoS One 8(6), e66517.

Kassahun F, Worku C, Nigussie A and Ganfurie G (2018) Prevalence of male attendance and associated factors at their partners antenatal visits among antenatal care attendees in Bale Zone, South East Ethiopia. International Journal of Nursing and Midwifery 10(9), 109-120.

Mahmood MA, Mufidah I, Scroggs S, Siddiqui AR, Raheel H et al. (2018) Root-cause analysis of persistently high maternal mortality in a rural district of Indonesia: role of clinical care quality and health services organizational factors. BioMed Research International 2018, 1-11

Mangeni JN, Nwangi A, Mbugua S and Mukthar VK (2012) Male involvement in maternal healthcare as a determinant of utilisation of skilled birth attendants in Kenya. East African Medical Journal 89(11), 372-383.

Matiang'i M, Mojola A and Githae M (2014) Male involvement in antenatal care redefined: a cross-sectional survey of married men in Lang'ata district, Kenya. African Journal of Midwifery and Women's Health 7(3), 117-122.

Mohammed BH, Johnston JM, Vackova D, Hassen SM and Yi H (2019) The role of male partner in utilization of maternal health care services in Ethiopia: a community-based couple study. BMC Pregnancy and Childbirth 19(1), 1-9.

Mon AS, Phyu MK, Thinkhamrop W and Thinkhamrop B (2018) Utilization of full postnatal care services among rural Myanmar women and its determinants: a cross-sectional study. F1000 Research 7, 1167.

MoPH (2016) National Health Strategy 2016-2020. Ministry of Public Health, Kabul, Afghanistan. URL: http://www. nationalplanningcycles.org/sites/default/files/planning_cycle_repository/afghanistan/afghanistan_mophstrategy2016-2020_ final09september2016111201614508950553325325.pdf (accessed July 2019).

MoPH (2017) National Reproductive, Maternal, Newborn, Child and Adolescent Health (RMNCAH) Strategy $2017-2021$. Ministry of Public Health, Kabul, Afghanistan. URL: http://rmncah-moph.gov.af/wp-content/uploads/2017/11/ National-RMNCAH-Strategy-2017-2021-English-Final.pdf (accessed June 2019). 
MoPH and KIT (2018) Afghanistan Health Survey (AHS) 2018. Ministry of Public Health, Kabul, Afghanistan, and KIT Royal Tropical Institute, Netherland. URL: https:/www.kit.nl/wp-content/uploads/2019/07/AHS-2018-report-FINAL15-4-2019.pdf (accessed July 2019).

Mullany BC, Becker S and Hindin MJ (2007) The impact of including husbands in antenatal health education services on maternal health practices in urban Nepal: results from a randomized controlled trial. Health Education Research 22(2), 166-176.

Mullany BC, Hindin MJ and Becker S (2005) Can women's autonomy impede male involvement in pregnancy health in Katmandu, Nepal? Social Science \& Medicine 61(9), 1993-2006.

National Institute of Statistics of Rwanda (NISR) (2010) Demographic and Health Survey Report 2010. Ministry of Health (MOH), Rwanda, and ICF International, Rockville, MD, USA. URL: https://dhsprogram.com/pubs/pdf/FR259/FR259.pdf (accessed July 2019).

Ongeso A and Okoth B (2018) Factors influencing male involvement in antenatal care among clients attending antenatal clinic: a case of Kenyatta National Hospital, Kenya. International Journal of Advanced Research 6(5), 72-82.

Rahman AE, Perkins J, Islam S, Siddique AB, Moinuddin M et al. (2018) Knowledge and involvement of husbands in maternal and newborn health in rural Bangladesh. BMC Pregnancy and Childbirth 18(1), 1-12.

Rahmani Z and Brekke M (2013) Antenatal and obstetric care in Afghanistan - a qualitative study among health care receivers and health care providers. BMC Health Services Research 13(1), 166.

Redshaw M and Henderson J (2013) Fathers' engagement in pregnancy and childbirth: evidence from a national survey. $B M C$ Pregnancy and Childbirth 13(1), 70.

Requejo J, Bryce J and Victora C (2015) Countdown to 2015: A Decade of Tracking Progress for Maternal, Newborn and Child Survival. The 2015 Report. UNICEF and World Health Organization, Washington DC, USA. URL: http://countdown2030. org/documents/2015Report/CDReport_2015_ex-profiles_final.pdf (accessed June 2019).

Richards E, Tolhurst R, and Theobald S (2011) Gender Influences on Child Survival, Health and Nutrition: A Narrative Review. Liverpool School of Tropical Medicine. URL: https://www.unicef.org/nutrition/files/Gender_Influences_on_ Child_Survival_a_Narrative_review.pdf (accessed June 2019).

Say L, Chou D, Gemmill A, Tunçalp Ö, Moller AB et al. (2014) Global causes of maternal death: a WHO systematic analysis. The Lancet Global Health 2(6), e323-e333.

Shahjahan M, Mumu SJ, Afroz A, Chowdhury HA, Kabir R and Ahmed K (2013) Determinants of male participation in reproductive healthcare services: a cross-sectional study. Reproductive Health 10(1), 27.

Shrestha S, Bell JS and Marais D (2014) An analysis of factors linked to the decline in maternal mortality in Nepal. PLoS One 9(4), e93029.

Story WT, Burgard SA, Lori JR, Taleb F, Ali NA and Hoque DE (2012) Husbands' involvement in delivery care utilization in rural Bangladesh: a qualitative study. BMC Pregnancy and Childbirth 12(1), 28.

Thapa DK and Niehof A (2013) Women's autonomy and husbands' involvement in maternal health care in Nepal. Social Science \& Medicine 93, 1-10.

Tokhi M, Comrie-Thomson L, Davis J, Portela A, Chersich M and Luchters S (2018) Involving men to improve maternal and newborn health: a systematic review of the effectiveness of interventions. PLoS One 13(1), e0191620.

Tweheyo R, Konde-Lule J, Tumwesigye NM and Sekandi JN (2010) Male partner attendance of skilled antenatal care in periurban Gulu district, Northern Uganda. BMC Pregnancy and Childbirth 10(1), 53.

United Nations (1995) United Nations Report of the Fourth World Conference on Women: Action for Equality, Development, and Peace. Beijing, China. URL: http://www.un.org/womenwatch/daw/beijing/pdf/Beijing\%20full\%20report\%20E.pdf (accessed June 2019).

United Nations (2012) Report of the International Conference on Population and Development. United Nations Publication, New York, USA. URL: http://www.un.org/en/development/desa/population/events/pdf/expert/27/SupportingDocuments/ A_CONF.171_13_Rev.1.pdf (accessed June 2019).

Van der Gaag N, Heilman B, Gupta T, Nembhard C and Barker G (2019) State of the World's Fathers: Unlocking the Power of Men's Care. Promundo-US, Washington DC. URL: https://men-care.org/wp-content/uploads/sites/3/2019/06/BLS19063_PRO_ SOWF_REPORT_015.pdf (accessed July 2019).

Varkey LC, Mishra A, Das A, Ottolenghi E, Huntington D et al. (2004) Involving Men in Maternity Care in India. Population Council, New Delhi, India. URL: http://www.popcouncil.org/pdfs/frontiers/FR_FinalReports/Indi_MIM.pdf (accessed June 2019).

Wai KM, Shibanuma A, Oo NN, Fillman TJ, Saw YM and Jimba M (2015) Are husbands involving in their spouses' utilization of maternal care services? A cross-sectional study in Yangon, Myanmar. PLoS One 10(12), 1-13, e0144135.

WHO (2002) WHO Antenatal Care Randomised Trial: Manual for the Implementation of the New Model. World Health Organization, Geneva, Switzerland. URL: https://apps.who.int/iris/bitstream/handle/10665/42513/WHO_RHR_01.30. pdf;jsessionid=901CD16026341643FFF5C8DE3301965C?sequence=1 (accessed April 2019).

WHO (2007) Standards for Maternal and Neonatal Care. Integrated Management of Pregnancy and Childbirth. World Health Organization, Geneva, Switzerland. URL: https://apps.who.int/iris/bitstream/handle/10665/69735/a91272.pdf?sequence=1 (accessed April 2019). 
WHO (2015) WHO Recommendations on Health Promotion Interventions for Maternal And Newborn Health. World Health Organization, Geneva, Switzerland. URL: https://apps.who.int/iris/bitstream/handle/10665/172427/9789241508742_report_ eng.pdf?sequence $=1$ (accessed June 2019).

WHO (2016) WHO Recommendations on Antenatal Care for a Positive Pregnancy Experience. World Health Organization, Geneva, Switzerland. URL: https://apps.who.int/iris/bitstream/handle/10665/250796/9789241549912-eng.pdf (accessed April 2019).

Yargawa J and Leonardi-Bee J (2015) Male involvement and maternal health outcomes: systematic review and metaanalysis. Journal of Epidemiology and Community Health, 69(6), 604-612.

Cite this article: Alemi S, Nakamura K, Rahman M, and Seino K (2021). Male participation in antenatal care and its influence on their pregnant partners' reproductive health care utilization: insight from the 2015 Afghanistan Demographic and Health Survey. Journal of Biosocial Science 53, 436-458. https://doi.org/10.1017/S0021932020000292 